\title{
Recommendations for reducing the risks of small businesses in the context of integration processes
}

\author{
Igor Alkhimovich ${ }^{1}$, Vera Pogodina ${ }^{2}$, and Nadezhda Anisimova ${ }^{3, *}$ \\ ${ }^{1}$ Moscow Pedagogical State University, 1/1 M. Pirogovskaya Str., Moscow, 119991, Russia \\ ${ }^{2}$ Saint Petersburg State Economic University, 21, Sadovaya Street, St. Petersburg, 191023, Russia \\ ${ }^{3}$ Voronezh State Technical University, 14, Moskovsky prospect, Voronezh, 394026, Russia
}

\begin{abstract}
The aim of this study is to develop methods to reduce the risk load on investment and construction enterprises based on the principles of self-organization. A model of formalizing the vector control function in the process of identifying a company in the investment and construction sector as a complex self-organizing system is proposed. A model of vector optimization of risk reduction for investment and construction companies has been formed, taking into account the difference in their interests and capabilities depending on the degree of integration. The optimality criteria of the model make it possible to reduce the risk coefficient by reducing the potential loss, increasing profits, and optimizing the ratio of own and borrowed funds. As a result of the study, a method was developed for the formation of a risk reduction mechanism in investment and construction companies, which is a set of step-by-step managerial actions for identifying risks and conducting anti-risk measures.
\end{abstract}

\section{Introduction}

The formation of a risk reduction mechanism at the enterprises of the real economy, in particular investment and construction companies, becomes especially relevant when the instability and unpredictability of the general economic and political situation in the country is strengthened. The main task of risk management is to ensure such a position of the company on the market when it is protected in a crisis situation and can overcome temporary difficulties, including financial ones, by using not only the resource potential, but also through various risk tools management. In this situation, the use of selforganization mechanisms in risk management can allow the investment and construction company to reach a qualitatively new level of development. As modern studies show, effective management of entrepreneurial risks is necessary not only in the economic, but also in the social, political environment, and the evolution of modern business demonstrates that the effective solution of risk reduction problems is largely based on the use of selforganization laws $[1,2]$.

\footnotetext{
* Corresponding author: anisimova@mail.ru
} 
The evolution of modern business indicates that an effective solution to the problems of the strategic development of an organization, including risk reduction, can be carried out, among other things, taking into account the laws of self-organization. The key conditions for classifying a system as self-organizing are the conditions of openness and disequilibrium, a company operating in the investment and construction sector satisfies these conditions [3].

\section{Materials and methods}

The development process of an investment and construction company can be presented as unequal, but static, in view of the existence of external factors supporting the degree of disequilibrium of internal conditions: the likelihood of exposure to internal and external risk-generating factors. For the case under consideration, this will be a search for ways out of the current situation, market research, the search for new contractors, the generation of new ideas. For this, an effective risk management system is required [4]. All this leads to the appearance of asymmetry, including a change in the organizational structure, ownership schemes and capital structure. As a result, we have the appearance of the phenomenon of self-organization, i.e. a transition to a qualitatively new level - to a new stage of project implementation [5].

Such a sequence of the process of self-organization under the influence of risks can occur at any stage of the project (Fig. 1.)

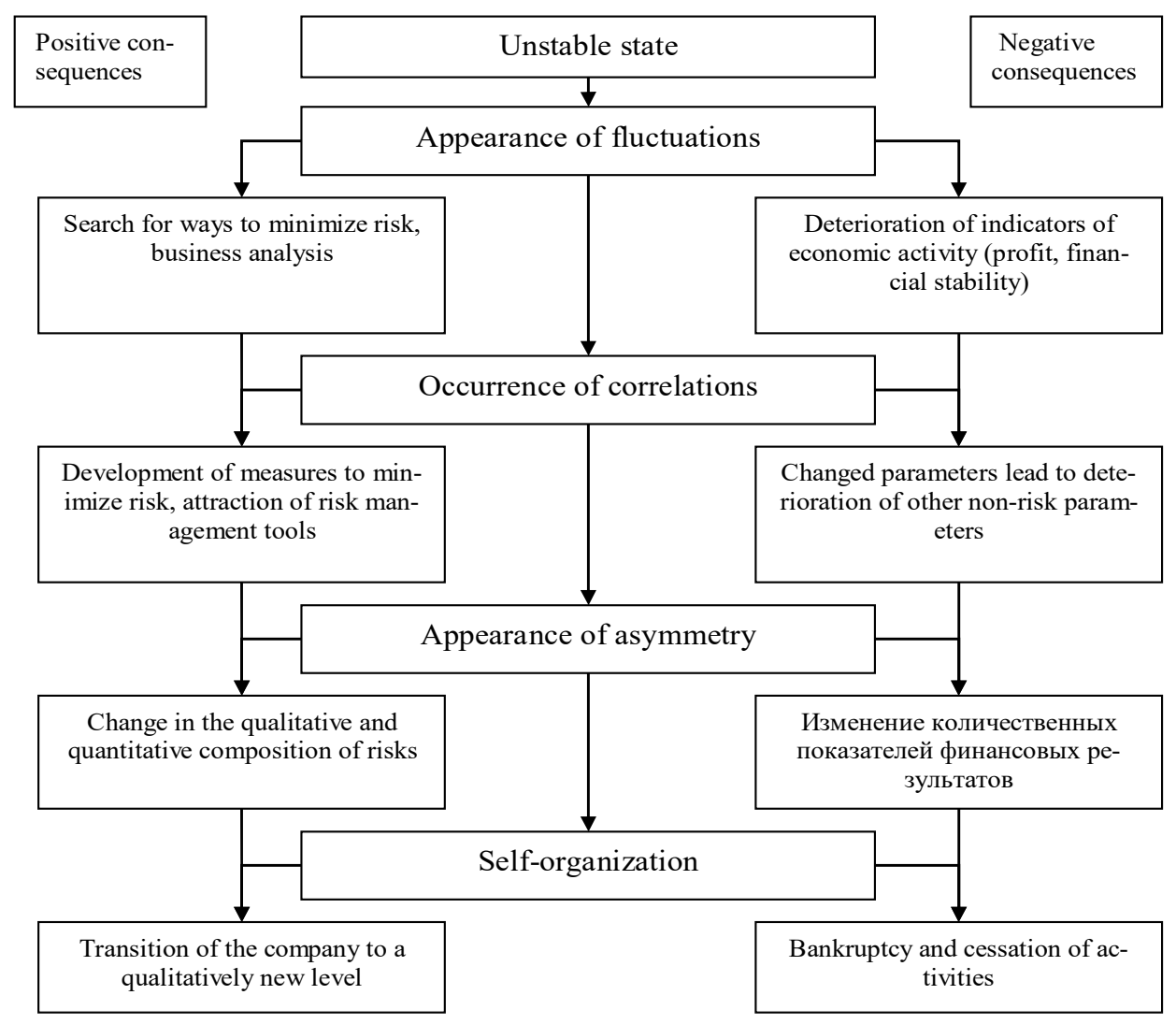

Fig. 1. Self-organization processes at various stages of the investment and construction project. 
This sequence demonstrates how through a series of stationary nonequilibrium states, moving from one stage of the project to another and from one project to another, an investment and construction company can achieve the highest level of development using the possibilities of self-organization.

In this regard, it is proposed to use the formalization model of the vector management function in the process of identifying investment and construction companies as a complex self-organizing system. This model is based on the allocation and consideration of stochastic factors, and allows selecting the most effective managerial influences when predicting the development of the company [6].

When considering an investment and construction company as a system, indicators that determine the degree of readiness of an investment and construction company to move to the next stage of the project can be used as an "input" $\left(\operatorname{In}_{0}(t)\right)$.

The identification problem is solved by analyzing information about the observations (N) of inputs $X$ and outputs Out of an object in normal operation. Comparison of the obtained information can be carried out using the formation of the residual function $\mathrm{Nev}$ of outputs of the model and the object. In the simplest case, it might look like this:

$$
\operatorname{Nev}(t, N)=\sum_{i=1}^{m}\left[\operatorname{Out}_{i 0}(t)-O u t_{i 1}(t)\right]^{2},
$$

where $\operatorname{Out}_{i 0}(t)$ - reaction of a real object to a given input action $X(t)$ on the i-th output; $\mathrm{Out}_{i l}(t, P)$ - corresponding (design) model output

At the first stage of the project (stage of the idea, development of the project) (Fig. 2.), the following conditions can be used as "input" $\left.\left(\operatorname{In}_{0}(t)\right): 1\right)$ maintenance supplies; 2) the plan for the construction of the facility; 3) labor resources.

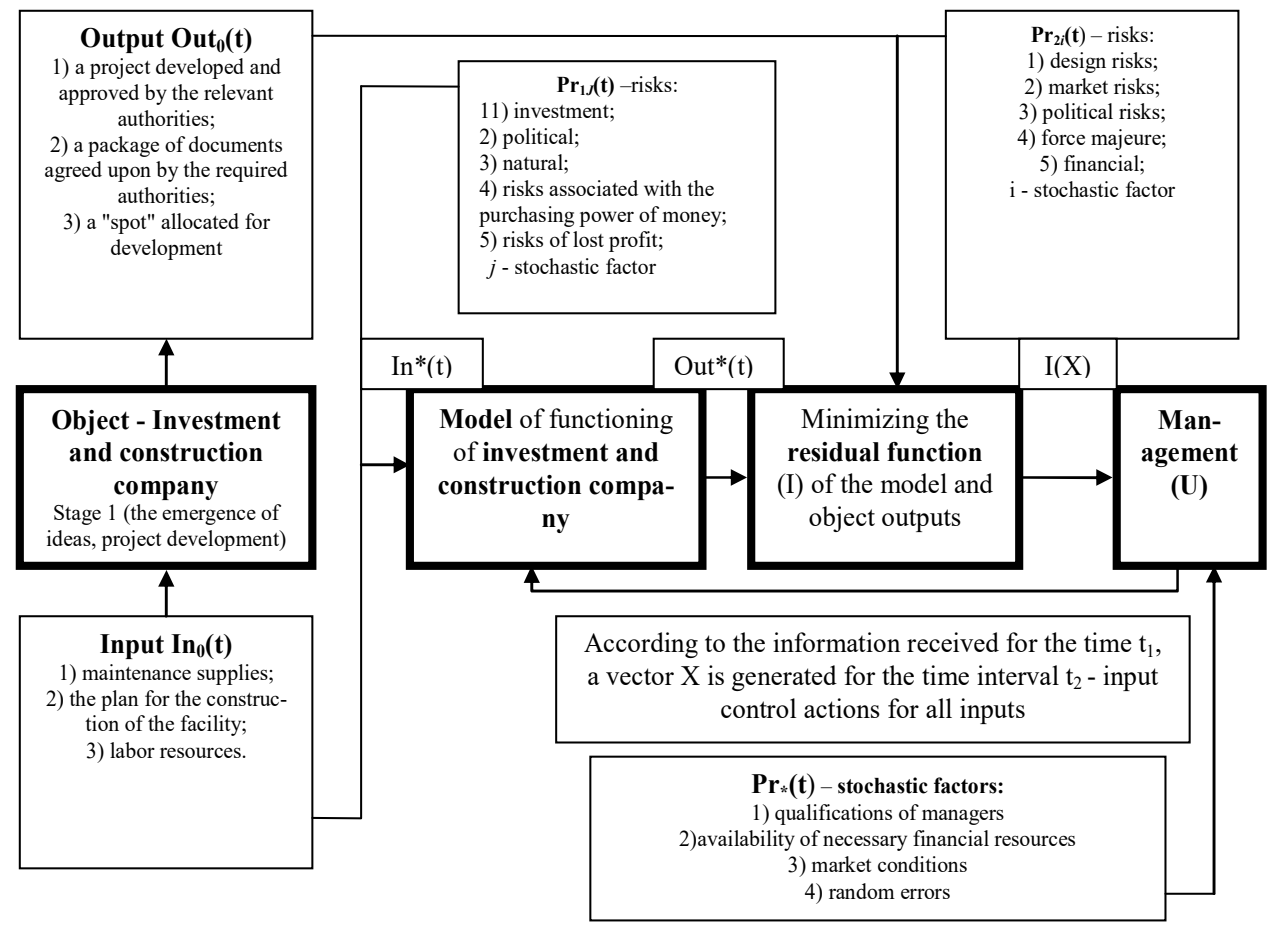

Fig. 2. Implementation of the vector management function at the first stage of the project in the investment and construction company. 
Designations: $\operatorname{Pr}_{\mathrm{J}}(\mathrm{t})$ - probabilistic, stochastic factors (risks) affecting the input $\operatorname{In}_{0}(\mathrm{t})$ of the system in a period of time $t ; j$ - the serial number of the factor affecting the input $(j=1$, $\mathrm{n}) ; \operatorname{Pr}_{\mathrm{i}}(\mathrm{t})$ - probabilistic, stochastic factors (risks) affecting the output $\mathrm{Out}_{0}(\mathrm{t})$ of the system in a period of time $t$; $i$ - the serial number of the factor affecting the output $(i=1, n)$; Input $\operatorname{In}_{0}(t)$ - indicators determining the readiness of the construction company to perform a certain stage of the object; Output $\operatorname{Out}_{0}(\mathrm{t})$ - indicators obtained at the output of the managed facility; $\operatorname{In} *(\mathrm{t})$ - distorted input of the model, which was affected by stochastic factors; Out*(t) - distorted output of the model, which was affected by stochastic factors; I(X) residual function of the outputs of the model and the object.

It is natural to assume that since the goal of the first stage of the construction and investment project in the study under consideration is the willingness and ability to proceed to the second stage, then the following conditions can be used as the "output" $\left(\mathrm{Out}_{0}(\mathrm{t})\right)$ of the managed object: 1 ) a project developed and approved by the relevant authorities; 2) a package of documents agreed upon by the required authorities; 3) a "spot" allocated for development.

The next step in formalization is the identification of the investment and construction company itself as a system, i.e. as an object of management.

There is a model of vector optimization of risk reduction, which takes into account the difference in their interests and capabilities depending on the degree of integration. The optimality criteria laid down in the model framework make it possible to reduce the risk factor by reducing the potential loss, increasing profits, and optimizing the ratio of own and borrowed funds [7].

It can be hypothesized that the higher the degree of integration, i.e. the more stages of an investment and construction project are implemented by one organization, the greater the size of the loss as a whole in case of negative risk events, but lower for each individual stage. Based on this, we can draw up a conditional matrix of risk coefficient values that are typical for different types of investment and construction companies (Table 1).

Table 1. The matrix of the risk coefficient values, characteristic for different types of companies in the investment and construction sector.

\begin{tabular}{|c|c|c|c|c|}
\hline & & \multicolumn{3}{|c|}{$\begin{array}{l}\text { Conventional values of the numerator of the risk coefficient - } \\
\mathrm{Y} \text { - the maximum possible amount of loss (rubles) }\end{array}$} \\
\hline & & $\mathrm{Y}_{\min }$ & $\ldots$ & $\mathrm{Y}_{\max }$ \\
\hline 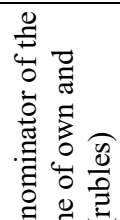 & 目 & $\begin{array}{l}\text { - Low degree of integration; } \\
\text { - Low degree of stability of the } \\
\text { company; } \\
\text { - High risks of external } \\
\text { interaction; } \\
\text { - Low risks of internal interaction }\end{array}$ & & $\begin{array}{l}\text { - High degree of integration; } \\
\text { - Low degree of stability of the } \\
\text { company; } \\
\text { - Low risks of external } \\
\text { interaction; } \\
\text { - High risks of internal interaction }\end{array}$ \\
\hline 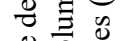 & $\vdots$ & & & \\
\hline 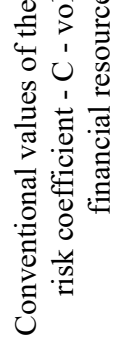 & $U^{\stackrel{\varpi}{\sharp}}$ & $\begin{array}{l}\text { - Low degree of integration; } \\
\text { - High stability of the company; } \\
\text { - High risks of external interaction; } \\
\text { - Low risks of internal interaction }\end{array}$ & & $\begin{array}{l}\text { - High degree of integration; } \\
\text { - High stability of the company; } \\
\text { - Low risks of external } \\
\text { interaction; } \\
\text { - High risks of internal } \\
\text { interaction }\end{array}$ \\
\hline
\end{tabular}

From this matrix, we can see that non-integrated companies (contractors, etc.) have the smallest financial risk. But for them, the risks of external interaction increase (search for counterparties, etc.), the negative implementation of which can lead to serious financial 
consequences, and companies with a high degree of integration and a large amount of financial resources may have less financial risk on each stage of the investment and construction project, but may encounter the problem of the negative realization of the risks of internal interaction (inefficient management, etc.).

Temporarily abstracting from non-material variables - the risks of internal and external interactions - one can try to formalize such a multi-criteria optimization problem using variables that have a financial expression.

The first criterion of optimality in the first problem will be, the maximum profit of the non-integrated company, the second - the maximum profit of the integrated company. The maximum value of the objective function in each case should be achieved in a certain economic space, which can be represented in the form of restrictions.

Accordingly, in the second task, the first criterion of optimality will be the minimum cost of the scope of work (potential loss) of the non-integrated company, the second - the minimum cost of the scope of work (potential loss) of the integrated company [8].

Thus, it is possible to formalize, for example, two vector optimization models for each of the options for forming a structure that implements a construction investment project.

1) It is necessary to maximize the vector function expressing the total profit of the company implementing the investment and construction project,

$$
\mathrm{F}\left(\mathrm{f}_{1}(\mathrm{X}), \mathrm{f}_{2}(\mathrm{X}, \mathrm{m})\right) \rightarrow \max ,
$$

where $f_{1}(X)=\left(p_{i-1}+c_{i}\right)\left(X_{i}-1\right) \rightarrow \max$ - profit of the organization at the $i$-th stage of the investment and construction project; $f_{2}(X, m)=(m-1) \sum_{j=1}^{n} c_{j} \cdot \rightarrow$ max $\quad$ - vertical company profit, $p_{i-1}-$ the cost of the scope of work at $i-1$ stage; $c_{i}-$ marginal costs of the $\mathrm{i}$-th company; $\mathrm{X}_{\mathrm{i}}$ - margin of the $\mathrm{i}$-th company; $\mathrm{m}$-the margin of a vertically integrated company.

2). It is necessary to minimize the vector function expressing the cumulative decrease in the cost of the scope of work (potential loss) of the company implementing the investment and construction project,

$$
\mathrm{F}\left(\mathrm{f}_{1}(\mathrm{X}), \mathrm{f}_{2}(\mathrm{X}, \mathrm{m})\right) \rightarrow \mathrm{min},
$$

where $f_{1}(X)=\left(p_{i-1}+c_{i}\right) X_{i} \rightarrow$ min- the cost of the company's work at the i-th stage of the investment construction project; $f_{1}(m)=\sum_{j=1}^{n} c_{j}, \rightarrow$ min - vertical company profit, $\mathrm{p}_{\mathrm{i}-1}$ - the cost of the scope of work at $\mathrm{i}$ - 1 stage; $c_{i}$ - marginal costs of the $\mathrm{i}$-th company; $\mathrm{X}_{\mathrm{i}}$ margin of the $\mathrm{i}$-th company; $\mathrm{m}$ - the margin of a vertically integrated company.

The following is a developed method for creating a risk reduction mechanism in investment and construction companies, which is a set of step-by-step managerial actions for identifying risks and conducting risk-free measures at each stage of the implementation of an investment and construction project. This method allows creating a system to minimize the risks of interaction, environmental and commercial risks. The scenario for the implementation of an investment construction project based on the principles of selforganization (see Fig. 3) allows us to offer concrete steps to form a risk management system at each stage of project development. 


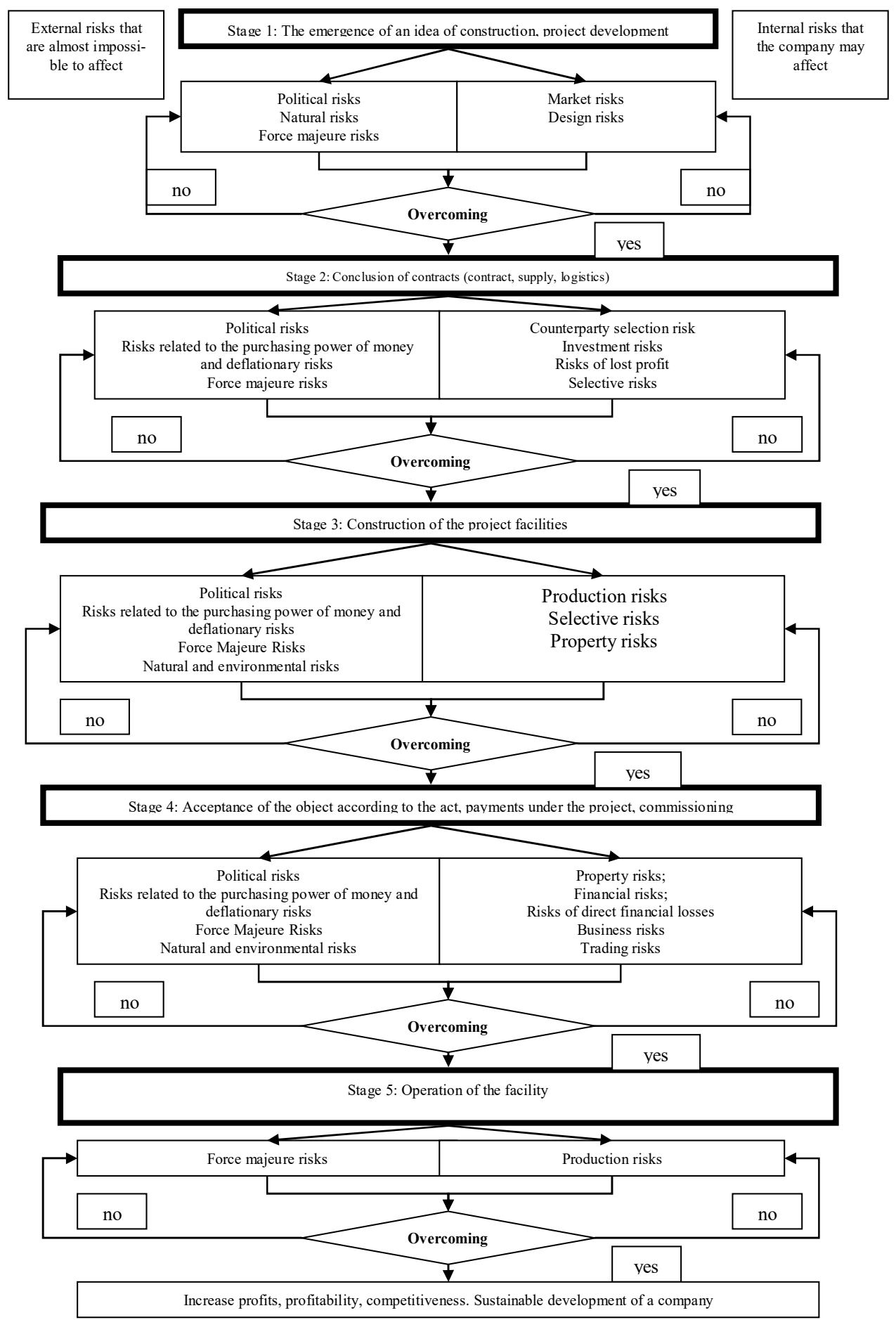

Fig. 3. Scenario for the implementation of an investment project for the construction of a glass factory based on the principles of self-organization. 
At stage I (emergence of the construction idea, project development), when developing risk management measures, investment and construction companies need to create a system of methods to minimize interaction risks.

At stage II (conclusion of contract, supply, logistics, etc.), when developing risk management measures, special attention should be paid to the choice of partners at the stage of concluding contracts, since it depends on whether the company has time to put an object into operation, whether it meets the planned estimated cost.

At stage III (construction of the facility), when developing risk management measures, it is most expedient to apply a regression analysis to formalize the probabilistic nature of the onset of risk, the use of which allows managing the main parameters of the investment and construction project with different probabilities in order to maintain its given effectiveness.

At stage IV (commissioning of an object under an act, payments under the project, commissioning), during the development of risk management measures, the development of an investment and construction company can be affected by property, financial, trade risks, and risks of direct financial losses.

At stage $\mathrm{V}$ of the implementation of the investment and construction project (operation of the facility), the formation of a special risk management system is not advisable due to the fact that the main risk, in our opinion, at this stage may be the risk of force majeure, which we regard as external, i.e., unmanageable risks. Therefore, in this case, the application of traditional insurance procedures may be recommended.

\section{Discussion}

An investment and construction project can be implemented by a different number of companies with a different number of risks. Therefore, the work concluded that it is advisable to consider the degree of integration of organizations as an important factor affecting the implementation of certain risk events. The selection and achievement of optimal values of the risk coefficient is a complex multi-criteria task that each company has to solve depending on the available capabilities and the prevailing conditions. In addition, it was concluded that a set of step-by-step managerial actions is needed to identify risks and conduct anti-risk measures at each stage of the investment construction project.

\section{Conclusion}

The methodological recommendations developed as a result of the study to reduce the risk load on investment and construction enterprises are based on the identification and consideration of stochastic factors and allow choosing the most effective managerial impacts when predicting the development of the company. This will help to identify the most important risks for each stage of the development of the investment construction project, the impact of which will be the most significant and tangible for the project, and to offer anti-risk measures to each risk group.

\section{References}

1. I.G. Lukmanova, N.Yu. Yaskova, Vestnik MGSU 14(6), 774-784 (2019) DOI: 10.22227/1997-0935.39.19.6.774-784

2. N.Yu. Yaskova, The Bulletin of Irkutsk State Technical University 10(81), 380-382 (2013) 
3. M. Bovsunovkaya, I. Saltykov, MATEC Web of Conf. 265, 07028 (2019) https://doi.org/10.1051/matecconf/201926507028

4. M.Yu. Mishlanova, Scientific Review 11, 339-341 (2015)

5. A.A. Gorobnyak, Procedia Engineering 165, 1287-1292 (2016)

6. I.G. Lukmanova, M.Y. Mishlanova, International Journal of Economics and Financial Issues 5, 208-216 (2015)

7. A.P. Khomenko, S.K. Kargapoltsev, A.V. Eliseev, MATEC Web of Conferences 148, 11004 (2018) https://doi.org/10.1051/matecconf/201814811004

8. V. Dikareva, V. Kankhva, MATEC Web of Conferences 106, 08022 (2017) https://doi.org/10.1051/matecconf/201710608022 